\title{
Assessment of the anthropogenic and natural risks in environmental and toxicological studies
}

\author{
G. Quartieri ${ }^{1,2}$, P. Quercia ${ }^{2}$, L. Quartieri ${ }^{3}$ \& P. Avino ${ }^{3,4}$ \\ ${ }^{1}$ Libera Università degli Studi di Lugano, Lugano, Switzerland \\ ${ }^{2}$ Institute for Basic Research, Florida, USA \\ ${ }^{3}$ Centro Studi di Biometeorologia, Rome, Italy \\ ${ }^{4}$ Laboratorio Chimico dell'Aria, DIPIA, ISPESL, Rome, Italy
}

\begin{abstract}
Nowadays among different factors acting on human life, one of the most important is related to environmental and energetic problems: what is the risk analysis between the natural and anthropogenic carbon produced in the atmosphere? In the meantime, the investigation between organic carbon (primary and secondary origins) and elemental carbon (primary origin) is of fundamental importance both for studying the pneumoconiogen and toxic effects and consequently understanding the mechanism formation of some atmospheric phenomena such as the photochemical pollutant production.

Keywords: carbon, anthropogenic sources, petroleum cave, natural risk, human health.
\end{abstract}

\section{Introduction}

Nowadays, one of the most important factors acting on human life is related to environmental and energetic problems: what is the risk analysis between the natural and anthropogenic carbon produced in the atmosphere? The answer to this question is becoming much more important due to the implications on both human health and energetic solutions, which will increase in the near future. For these reasons, the measurement of organic carbon (OC) and elemental carbon (EC) assume fundamental aspects especially for evaluating the air quality resulting from the combustion process [1]. For instance, in urban areas these measurements allow definition of a specific index of autovehicular traffic and domestic heating (anthropogenic factors) for their persistence in air giving 
significant effects on human health and participating in various physicalchemical reactions in the atmosphere. A good example of these considerations is represented by the picture of downtown Rome: the good correlation between OC and EC values evidences the autovehicular traffic as the most important source of carbonaceous fraction in that area.

Actually, in nature other anthropogenic risks are present so it is very difficult to get a balance of natural and anthropogenic without considering them both in urban and/or in remote areas. For instance, the risk produced by petroleum research and relative excavations forming underground caves down to $20 \mathrm{~km}$ and altering the earth equilibrium should be considered.

In this paper an assessment of anthropogenic and natural risks is reported. Attention is drawn to two particular situations deriving from anthropogenic activities in two different areas such as the urban areas and the petroleum caves.

\section{Experimental}

\subsection{Sampling sites}

Aerosol samples were collected at a height of $4 \mathrm{~m}$ from road level in a monitoring station situated inside a green park (Villa Ada Park): this site is not directly influenced by anthropogenic emissions.

\subsection{Measurement method}

Total Carbon (TC), EC and OC were measured by means of an Ambient Carbon Particulate Monitor 5400 (Rupprecht \& Patashnik Co Inc., USA) equipped with a non-dispersive infrared detector (NDIR). OC is separated and analysed at $350^{\circ} \mathrm{C}$ as $\mathrm{CO}_{2}$ after oxidation; the remaining carbon is then oxidized to $\mathrm{CO}_{2}$ at $750^{\circ} \mathrm{C}$ and measured. EC is obtained from the difference of TC and OC [2]. PM10 was monitored by a TEOM Ambient Particulate Monitor (R\&P).

\section{Results and discussion}

\subsection{Anthropogenic risks in urban areas}

The portion coming from the anthropogenic sources is composed of two classes of compounds: one is inorganic (e.g., metals, sulphates, nitrates, ammonium, etc.) and one is a carbonaceous fraction. In particular, the carbonaceous material is considered an important parameter for urban air quality evaluation. TC is the sum of EC and OC. Since most combustion sources are anthropogenic and generally EC does not undergo chemical transformations, EC is a good indicator of primary anthropogenic primary pollution. OC is emitted from primary anthropogenic and biogenic emission sources [3] but it can also be generated by chemical reactions among primary gaseous OC species in atmosphere [4].

Figure 1 shows the temporal trends of PM10 and TC from $14^{\text {th }}$ to $26^{\text {th }}$ of November 2002. The PM and TC trends are very similar. When stability conditions are present $\left(17^{\text {th }}-23^{\text {rd }}\right.$ and $\left.25^{\text {th }}\right)$ the PM and TC concentrations show 
the following pattern: maximum values in the morning and relative minimum values in the late afternoon evening. During the days $15^{\text {th }}, 16^{\text {th }}$ and $24^{\text {th }}, \mathrm{PM}$ and TC concentrations decrease considerably. These PM and TC temporal trends are typical of primary pollutants and they can be easily interpreted because the dynamic boundary layer evolution is well defined.

Figure 2 reports the temporal $\mathrm{OC}$ and $\mathrm{EC}$ trends and the relative correlation during the same period. EC and $\mathrm{OC}$ concentrations have a very similar modulation and they show a very good correlation $\left(\mathrm{R}^{2}=0.96\right)$. When the stability conditions are present, the maximum EC concentrations are higher than the OC ones whereas during instability periods $\left(22^{\text {nd }}, 25^{\text {th }}\right.$ and $\left.26^{\text {th }}\right)$ the EC and OC values are similar. The large correlation coefficients between $\mathrm{EC}$ and $\mathrm{OC}$ in Rome permit us to infer that $\mathrm{EC}$ and $\mathrm{OC}$ have an important origin in motor vehicle emissions.

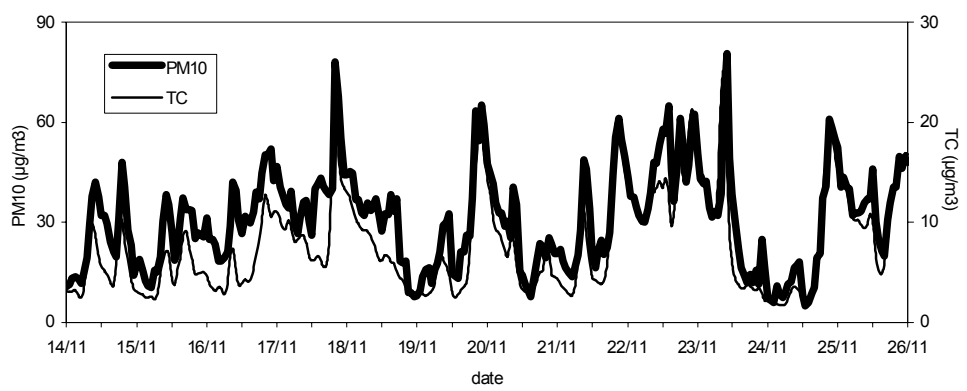

Figure 1: $\quad$ PM10 temporal trends from 14-26 November 2002.

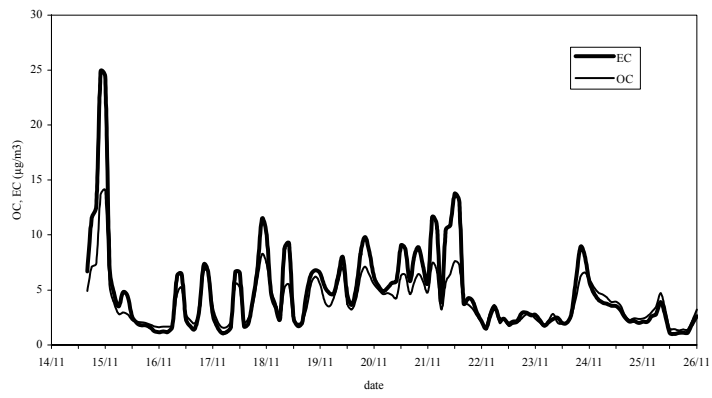

Figure 2: $\quad$ Daily trends of OC and EC from 14-26 November 2002.

According to the different and possible primary and secondary sources present in urban areas, an attempt of PM10 mass balance is reported in Figure 3. The sampling and analysis procedure is reported in previous papers [5].

The TC ranges between 25 and $40 \%$ depending on the sampling sites in downtown and in remote places. The EC fraction is essentially composed of no easily identifiable primary pollutants; the OC fraction has a large fraction of unidentified compounds (85-90\%) and a small portion (10-15\%) of three 


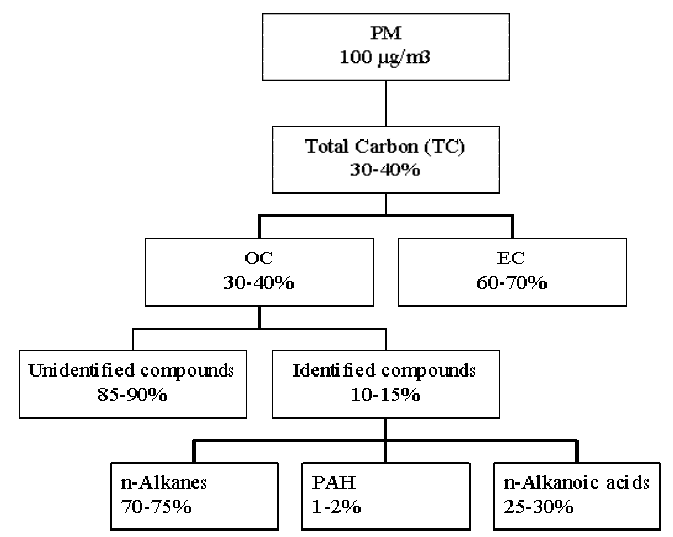

Figure 3: $\quad$ Master scheme of the PM10 mass balance in Rome.

different compound classes, n-alkanes and Polycyclic Aromatic Hydrocarbons (PAHs) and n-alkanoic acids, coming from primary (combustion processes and biogenic emissions) and secondary (gas-to-particle conversion) sources.

\subsection{Risks from seismic phenomena after anthropogenic activities}

The aim is to find the correlation between the existence of some local underground vacuum holes produced by oil and natural gas spilling and the possibility that they can cause initialisation and/or amplify a relatively local earthquake due to some other seismic wave coming from other (near or far) places where an earthquake has happened. Recently, two basic seismic events such as the San Giuliano (Molise, 31 October 2001) earthquake and the Algeria earthquake (2003) support the idea itself. The two earthquake sites are in areas in which natural gas has been spilled for a period lasting at least two decades. Throughout the years, this activity has greatly increased the level of local seismicity, due to a huge amount of reduction in the vacuum cave roof mechanical resistance and the increment of rigidity and stiffness.

The correlation between seismic wave that meets an Earth vacuum hole and the production of a local earthquake seems very far from a concrete and substantiated scientific event. However, starting from classic seismology theory it is possible to easily deduce the presence of an elementary singularity and/or discontinuity along the propagation pattern of $\mathrm{P}$ and $\mathrm{S}$ surface wave i.e. at shallow Earth depth in the presence of an artificial air-vacuum hole (Figure 4).

As Earth medium density $\rho$ goes to zero in correspondence to the vacuum hole produced by oil and/or natural gas spilling, do the classic Laplace coefficients $\alpha$ and $\beta$ go to infinity, i.e. the square speed of the waves become infinite, providing a singularity and a loss of sense for the wave itself. This singularity can imply a resonance of the cave roof producing a domino effect of roof collapse that, somehow, could produce an earthquake along the vertical direction itself. 


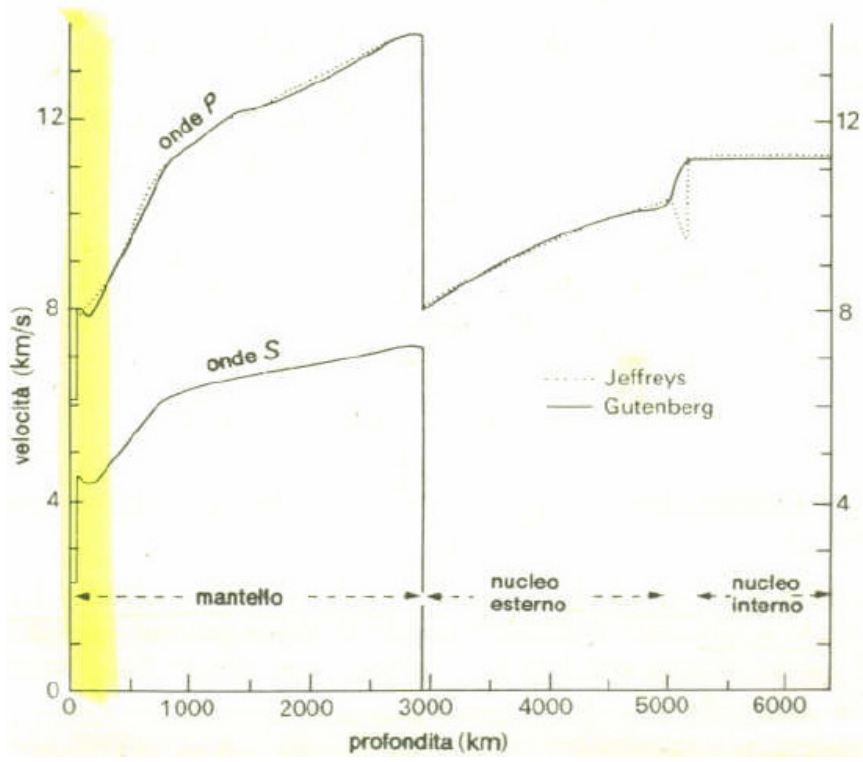

Figure 4: $\quad \mathrm{P}$ and $\mathrm{S}$ wave propagation speed inside the Earth.

This singularity has to be considered completely different from the W. Gutemberg one found in the classic seismology theory. This new singularity can be reduced to a classic non linear problem from the mathematical stand point, but, in practice, the point to argue is if this singularity can produce enough mechanical energy to initialise the start of a natural earthquake completely different from the classic earthquakes found in the standard geophysics volcanology and classic seismology.

The primary difference can be deduced between local anthropogenic risk and natural spread risk. In any case, carbon local risk aims at increasing rapidly as demonstrated by curves and the historical data set of different authors, such as Nobel Peace Prize winner Al Gore. In particular, the carbon dioxide risk has exponentially increased during these last 60 years with a ratio never seen during the previous eras.

In such a context, the anthropogenic component becomes increasingly important and fundamental so as to request and impose serious and important choices of different lifestyles.

\section{Conclusion}

This paper regards two different and fundamental risks occurring after anthropogenic activities: the exposure to combustion process effects (carbonaceous fractions of the particulate matter) and the presence of big caves underground due to petroleum/gas excavations. 
The carbonaceous fraction measure can be defined as a very important and fundamental task for the air quality evaluation in urban areas: in fact, this information represents a specific index of the pollution from autovehicular traffic. Further, the separation of EC and OC is important for the study of the formation mechanisms of the photochemical pollutants. In the meantime, the investigation between $\mathrm{OC}$ and $\mathrm{EC}$ is of fundamental importance for both studying the pneumoconiogen and toxic effects and consequently understanding the mechanism formation of photochemical pollutants. The first immediate consequence is that the carbon locally can be considered as severe for human health as other environmental factors (e.g. the greenhouse effect).

Regarding the second phenomena, i.e. the risk occurring after human excavations, the interesting point is that these unnatural phenomena are not totally recognized by the scientific community even if they are well-documented. So there are very few researches in this field because the eventual prospecting of geodynamic and acoustical researches are conducted mainly for finding any other oil and/or natural gas source. However, the above mentioned simple and elementary reasons eliminate all the blind classic approaches based on simple seismic measurements limited to a very superficial depth of the Earth.

\section{References}

[1] Avino, P., Brocco, D., Pareti, S., Scalisi, G. Description of the carbonaceous particulate matter evolution in an urban area. Annali di Chimica, 93, pp. 2126, 2003.

[2] Avino, P., Brocco, D., Lepore, L. Determination of atmospheric organic and elemental carbon particle in Rome with a thermal method. Analytical Letters, 34, pp. 967-97, 2001.

[3] Turpin, B.J., Huntzicker, J.J. Identification of secondary organic aerosol episodes and quantitation of primary and secondary organic aerosol concentrations during SQAQS. Atmospheric Environment, 29, pp. 35273544, 1995.

[4] Pitts, J.N. Jr., Van Cauwenberghe, K.A., Grosjean, D., Schmid, J.P., Fitz, D.R., Belser, W.L. Jr., Knudson, G.B., Hynds, P.M. Atmospheric reactions of polycyclic aromatic hydrocarbons: facile formation of mutagenic nitro derivatives. Science, 202, pp. 515-519, 1978.

[5] Avino, P., Brocco, D., Cecinato, A. Carbonaceous material, alkanes, Longchain carboxylic acids and PAHs in PM10: concentration levels and sources in Rome. In: "Air Pollution X", C. Brebbia (Ed.), WIT Press, Wessex, UK, 2002, pp. 693-700. 